\title{
ВКЛАД ТРУДОВЫХ МИГРАНТОВ В ЭКОНОМИЧЕСКОЕ РАЗВИТИЕ РЕСПУБЛИКИ ТАДЖИКИСТАН
}

\author{
(c) 2021 Сафиуллин Ленар Наилевич \\ доктор экономических наук, профессор, Институт управления, экономики и финансов \\ Казанский (Приволжский) федеральный университет, Россия, Казань \\ E-mail: lenar_s@mail.ru \\ (c) 2021 Сархатов Рамазон Исматович \\ аспирант \\ Казанский (Приволжский) федеральный университет, Россия, Казань \\ E-mail: sarkhatov93@mail.ru
}

Глобальные организации по миграции и развитию признали связь между миграцией и экономическим развитием. Влияние трудовой миграции особенно важно для Республики Таджикистан по нескольким причинам. Таджикистан переживает структурные изменения в процессе перехода от советской экономики. Поэтому влияние трудовой миграции на экономическое развитие особенно важно, поскольку у нас есть возможность наблюдать взаимодействие миграции и других показателей экономического развития в контексте общего процесса экономической трансформации. Во-вторых, Таджикистан - одна из тех стран, которые испытали чрезвычайно высокий уровень трудовой миграции за последнее десятилетие. Учитывая этот факт, интересно увидеть связь между развитием экономики в постсоветском Таджикистане и трудовой миграцией.

Ключевые слова: миграция, трудовая миграция, экономическое влияние миграции, экономика Республики Таджикистан, влияние миграции на экономику, денежные переводы мигрантов.

Таджикистан - отличный пример той роли, которую трудовая миграция играет в жизни страны и всего региона. Прежде всего, это денежные переводы мигрантов. 10-15 лет назад их объемы равнялись половине ВВП страны. В настоящее время доля переводов мигрантов только из России составляет более 30\% ВВП Таджикистана, а в абсолютном выражении - около 2,5 млрд. долларов [1]. По официальным данным, за последние годы (2013-2020 гг.) трудовые мигранты перевели только по официальным каналам, то есть через банки, более 15 млрд. долларов, что во много раз превышает объем прямых инвестиций, привлеченных за тот же период в Таджикистан [2].
Большинство таджикских трудовых мигрантов пытаются отправить домой львиную долю своего заработка. В соответствии с сезонным характером труда мигрантов, кривая денежных переводов достигает пика в период с сентября по ноябрь. Объем денежных переводов снижается с декабря, когда мигранты возвращаются в Таджикистан на зиму.

Средняя сумма одного перевода, согласно данным Центробанка России, составила в первой половине этого года, \$145. Для сравнения, средний размер одного перевода гражданами Узбекистана составил \$350, Армении - \$305, Азербайджана - \$295, Кыргызстана - \$200 (рис. 1) [17].

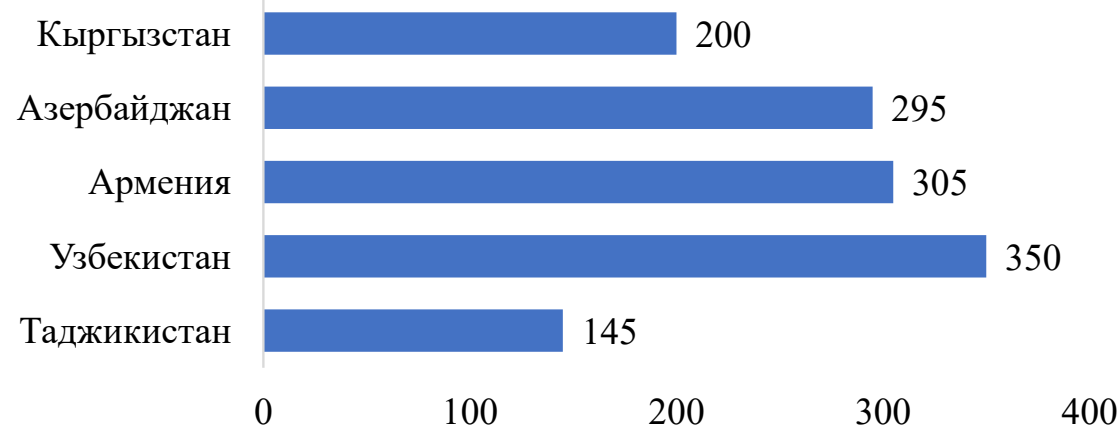

Puc. 1. Средняя сумма одного денежного перевода из России мигрантами из стран СНГ, долл. США 
Наибольшее число переводов осуществляется в Екатеринбурге, Иркутске, Красноярске, Москве, Санкт-Петербурге, Сургуте и Тюмени. Этот список коррелирует с данными обследования о том, где сконцентрированы мигранты и в каких областях они работают. В этих российских городах и близлежащих регионах проживает наибольшее число таджикских общин мигрантов и наибольшее число самых высокооплачиваемых среди различных групп мигрантов: челноков, людей, работающих на рынках, работников нефтегазовой отрасли. Гораздо меньшие суммы перечисляются из южных регионов России, где мигранты работают за сравнительно низкую заработную плату в качестве сельскохозяйственных рабочих и строителей в Волгоградской и Саратовской областях $[8,14]$.

Географические районы, получающие наибольшее количество денежных переводов, можно условно разделить на три группы [2].

Первая группа состоит из крупных городских ячеек, таких как Душанбе, Худжанд и Истаравшан (бывший Уро-Теппа). Большинство мигрантов, работающих в сфере торговли и услуг, приезжают из городов. Часть их доходов из-за рубежа вкладывается в малый и средний бизнес в этих традиционных городских торговых центрах. Однако без надлежащей правовой базы этот сектор не развивается так быстро, как это было бы возможно.

Вторая группа включает бедные, обычно горные районы с самым низким доходом на душу населения, в том числе Эшт, Пенджикент, Айни, Шахристан и Кухистони-Мастчох. Обеспечивая столь необходимый доход, денежные переводы помогают сглаживать региональные диспропорции.

Третью группу составляют промышленные районы, где добывается и перерабатывается углеводородное сырье. Трудовые мигранты из таких районов, как Ашт, Канибадам или Исфара, как правило, обладают высокой квалификацией. Поскольку у них есть квалификация, востребованная в России, им не трудно найти хорошо оплачиваемую работу в энергетическом секторе этой страны.

Денежные переводы мигрантов стали жизненно важными для таджикской экономики. В 2019-2020 гг. платежный баланс страны улучшился благодаря денежным переводам в иностранной валюте. Таджикские импортеры, включая крупных дистрибьюторов с банковским финансированием, получают доступ к иностранной валюте. Денежные переводы стимулируют потребительский спрос и заполняют пробелы в предложении товаров [6].

Следует отметить, что когда таджикские мигранты используют официальные каналы для отправки денег домой, банковская система России также извлекает выгоду.

Трудовая миграция оказывает негативное влияние на таджикскую экономику, например, замедляя рост внутреннего производства. Тем не менее, денежные переводы мигрантов, несомненно, способствовали стабилизации экономики и будут продолжать это делать в ближайшие годы.

Во всех постсоветских странах внешняя трудовая миграция является стратегией выживания домохозяйств, пытающихся преодолеть кризисные условия. Работая за рубежом, мигранты могут прокормить свои семьи и удовлетворить другие основные потребности. Домашние хозяйства мигрантов гораздо лучше оснащены товарами длительного пользования, дорогостоящей бытовой техникой и автомобилями, чем домашние хозяйства не мигрантов.

В случае Таджикистана семейный аспект является всеохватывающим. Почти все домохозяйства мигрантов интегрированы как в семейные, так и в этнорегиональные сети. Почти три четверти домохозяйств мигрантов прямо или косвенно оказывают помощь или поддержку нескольким родственным домохозяйствам.

Именно потому, что доходы, которые она приносит, должны быть распределены, миграция не приводит к быстрому улучшению благосостояния отдельных семей. Она едва увеличивает различия в уровне благосостояния в обществе.

Миграция не привела ни к индивидуальному накоплению богатства, ни к ускорению темпов развития отечественного малого и среднего бизнеса. Тем не менее, как стратегия выживания всего общества, трудовая миграция стала важнейшим стабилизирующим фактором, компенсирующим последствия экономического кризиca.

Она также привела к появлению широкой части населения, обладающей высокой мотивацией, активностью и мобильностью. Помимо улучшения материального положения своих семей и связанных с ними групп, они начали вкладывать средства в жилищное строительство, образова- 
ние детей, малый и средний бизнес, дехканские хозяйства, приобретение сельскохозяйственной техники и оборудования, новых сортов семян.

В то же время временная миграция молодых людей имеет смешанные последствия для развития страны. С одной стороны, их отсутствие способствует вовлечению таджикских женщин в экономическую деятельность. Однако отток наиболее динамичных и образованных членов общества приводит к снижению эффективности внутреннего сельского хозяйства, росту низкооплачиваемого ручного труда и распространению натурального хозяйства [5].

Уровень жизни домохозяйств мигрантов в Таджикистане выше среднего. По субъективным оценкам, 30,1\% домохозяйств мигрантов считают себя бедными по сравнению с более чем 65\% от общей численности населения. Для подавляющего большинства мигрантов работа за границей - это единственная открытая для них возможность прокормить семью (рис. 2) [9].

Для большинства домохозяйств мигрантов вопрос выживания стал менее острым (рис. 3) [9].
В 81,7\% случаев доходы мигрантов составляют один из основных источников доходов их домохозяйств. 42,5\% домохозяйств мигрантов зависят от заработной платы государственного предприятия как одного из основных источников доходов семьи (рис. 4) [9].

Данные Госкомстата показывают, что для сегмента населения Таджикистана с самыми высокими доходами заработная плата является основным источником доходов (42\% доходов). Второе место занимает продажа личных вещей и крупного рогатого скота (15\%). Затем следуют денежные переводы мигрантов (12\%), за которыми следует продажа урожая и продуктов питания. Гуманитарная помощь составляет 4\% доходов, а социальная выплата $-5 \%$. Если сравнить эти цифры с показателями для домохозяйств мигрантов, то можно увидеть, что заработная плата остается важнейшим источником доходов как для семей мигрантов, так и для семей со средним уровнем доходов [17].

Но в остальном структура доходов для этих двух групп резко различается. Если семьи со

\begin{tabular}{|c|c|}
\hline Нет ответа & $0,7 \%$ \\
\hline $\begin{array}{c}\text { У меня были большие долги, которые я } \\
\text { до сих пор выплачиваю }\end{array}$ & $0,8 \%$ \\
\hline Сложно сказать & $3,3 \%$ \\
\hline Почти без изменений & $13,0 \%$ \\
\hline Улучшено & \\
\hline Значительно улучшено & $14,8 \%$ \\
\hline
\end{tabular}

Puc. 2. Как изменилось финансовое положение семей трудовых мигрантов

Нет денег на хлеб $\quad 1,9 \%$

Едва сводим концы с концами. $28,2 \%$

Более или менее нормально $62,5 \%$

Хорошо, без финансовых проблем $7,4 \%$

Рис. 3. Оценки мигрантами финансового положения своих домохозяйств 


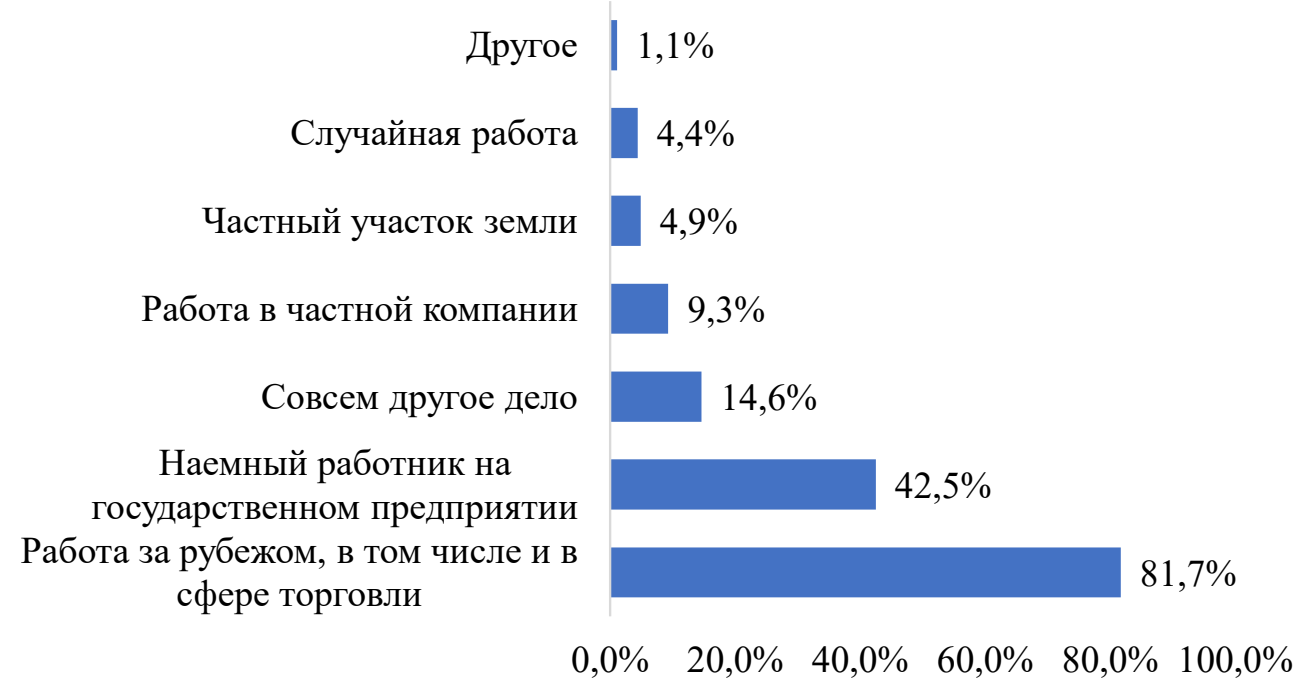

Puc. 4. Основные источники дохода домохозяйств мигрантов

средним уровнем дохода в основном получают 15\% доходов от продажи личных вещей и 10\% от продажи сельскохозяйственной продукции, то домохозяйства мигрантов получают 0,3\% и 4,9\% соответственно (от частных хозяйств).

Помимо доходов от миграции и заработной платы, которые являются вторым важным источником доходов, домохозяйства мигрантов получают базовые доходы от собственного бизнеса $(14,5 \%)$ и работы в частном секторе (9,3\%). Это означает, что трудовая миграция стимулирует предпринимательскую инициативу и создает возможности, пусть и малые, для развития малого и среднего бизнеса [17].

Еще одним свидетельством динамичного развития домохозяйств мигрантов является тот факт, что для 4,4\% из них эпизодическая работа становится основным источником дохода помимо работы за рубежом. Опыт ведения бизнеса, полученный при работе за рубежом, облегчает мигрантам поиск работы в будущем. Это также укрепляет их независимость. Они могут реагировать на изменение спроса на конкретные услуги. С другой стороны, когда они находятся на родине в зимние месяцы, у них нет возможности начать собственное дело [6].

Поступления от миграции обеспечивают благополучие семей мигрантов и увеличивают их инвестиционный потенциал. Следует отметить, что существуют различия между использованием средств, которые переводятся или посылаются через друзей или родственников, и использованием денежных сбережений, которые мигранты приносят с собой, когда они посещают свои семьи. В первом случае деньги в ос- новном расходуются на потребление продуктов питания или товаров первой необходимости. Во втором случае сбережения, скорее всего, будут использованы на крупные покупки, такие как квартиры или дома, или на семейные торжества, такие как свадьба или солнечный день (церемония обрезания) [17].

Исследования показывают, что мигранты начали вкладывать средства в различные виды собственности. Наиболее успешные мигранты предпочитают инвестировать в недвижимость, включая квартиры, дома, земельные права и развитие недвижимости. Значительная сумма денег идет на финансовую помощь родственникам. 25,8\% мигрантов постоянно поддерживают своих родственников за счет денег, заработанных за границей, а 46,3\% оказывают им эпизодическую поддержку [4].

Главной финансовой выгодой Таджикистана от экспорта рабочей силы является благоприятное влияние доходов мигрантов на платежный баланс страны. Однако, когда доходы мигрантов используются исключительно на потребление, внезапный, быстрый приток может спровоцировать инфляцию. Например, цена квартиры в Душанбе удвоилась в связи с резким ростом активности мигрантов на рынке недвижимости с августа по октябрь 2020 года. Однако доходы мигрантов не внесли существенного вклада во внутреннюю инфляцию, поскольку мигранты обычно покупают автомобили и дорогостоящие товары длительного пользования, такие как электроника и бытовая техника, пока они находятся за границей [12].

Несмотря на повышение покупательной спо- 
собности, трудовая миграция явно не приносит богатства. Даже те мигранты, которые улучшили материальное положение своих семей, находятся в относительно лучшем положении. Единственной недвижимостью, которой они владеют, является квартира или дом, в котором они живут, и они не накопили существенного капитала и не создали средств производства (рис. 5) [11].

Заработки мигрантов не оказали существенного влияния на развитие малого бизнеса. Результаты опроса показывают, что мигранты хотели бы накопить достаточно денег, чтобы начать свой собственный бизнес. Но вложения пока невелики. Лишь 3,8\% опрошенных мигрантов действительно открыли свое дело, и только
16,1\% смогли сэкономить на этом. 1,4\% наняли дополнительных работников, а 5,2\% оказали помощь своим детям или другим родственникам, чтобы они могли начать свой бизнес (рис. 6) [7].

Наибольший положительный эффект миграции - это наличие дополнительных ресурсов, которые можно потратить на образование в семьях, получающих денежные переводы. Дети из семей мигрантов имеют более сильные стимулы к изучению иностранных языков, имеют лучший доступ к техническому оборудованию, а их родители обычно имеют более широкий кругозор, однако в этих семьях также наблюдается более высокий уровень прогулов в школе, поскольку дети менее подвержены родительскому

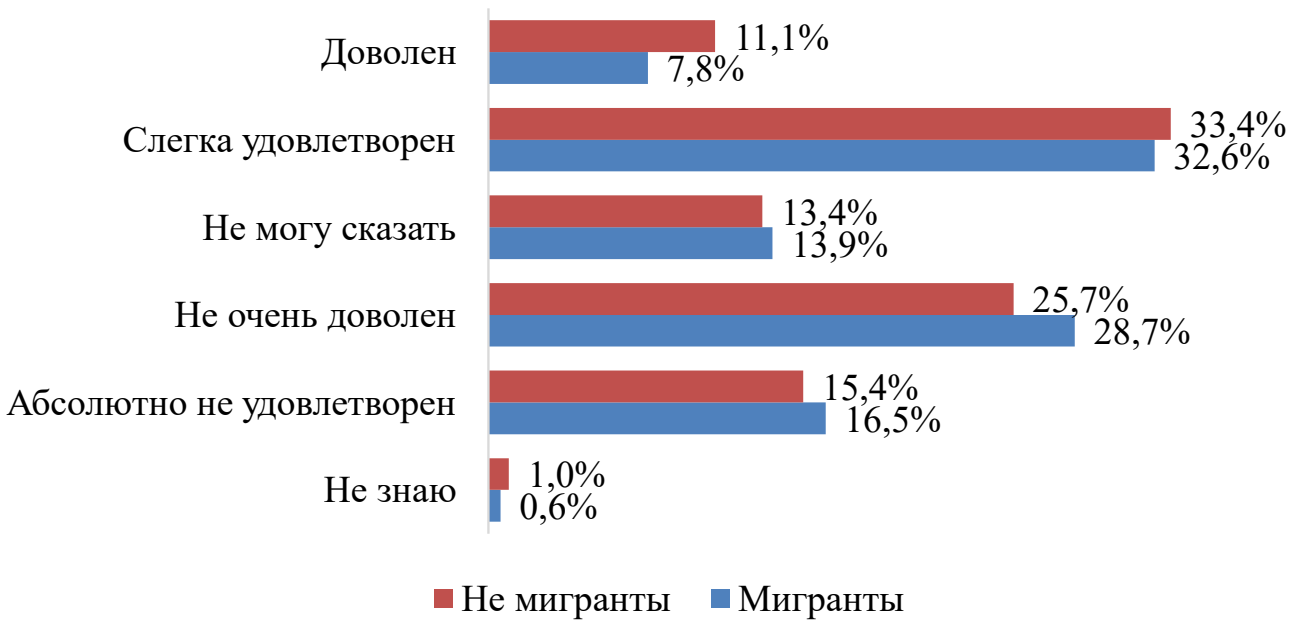

Puc. 5. Структура населения, кому удалось открыть или поддержать собственный бизнес

Нет

Помог своим детям или другим родственникам открыть частный бизнес

Нанял сотрудников для своего бизнеса

Открыл частный бизнес

Отложил начальные средства на открытие частного бизнеса

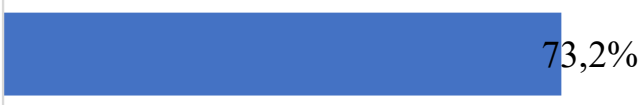

$5,2 \%$

$1,6 \%$

$3,8 \%$ 
контролю и с большей вероятностью надо работать [13].

Особое внимание необходимо уделять воздействию денежных переводов на экономическое развитие и борьбу с бедностью, состояние финансовой сферы и макроэкономики, а также изучению положительного опыта других стран интенсивной трудовой миграции.

Как показывает практика, с течением времени всё больше таджикских мигрантов остаются за рубежом и прекращают свои переводы на родину. Как правило, из страны уезжают молодые, предприимчивые и наиболее способные люди, большое количество интеллигенции, тем самым ослабляя развитие страны [10].

Сокращение отрицательных последствий и увеличение положительного эффекта, как для доноров, так и для реципиентов, от использования труда и переводимых материальных средств, произойдет только при правильном и эффективном использовании государственного контроля, государственной политики и модернизации существующих систем.

\section{Библиографический список}

1. ВВП на душу населения стран мира // InfoTables.ru.- Режим доступа: https://infotables.ru/ statistika/43-ekonomicheskaya-statistika-stran-mira/425-vvp-na-dushu-naseleniya-stran-mira-tablitsa \#hcq=hD9hWcs.

2. Мигранты отправляют в Таджикистан гораздо больше денег, чем иностранные инвестиции, поступающие в страну. Авеста. http://avesta.tj/2020/12/27/migranty-otpravlyayut-v-tadzhikistan-gorazdo-bolshe-denegchem-postupayushhie-v-stranu-inostrannye-investitsii.

3. Отраслевая структура занятости на рынке труда республики Таджикистан в годы суверенитета / Р. С. Ахмеджонова, Ф.Д.Ибодуллоева, Н.Р. Муминова // Таджикский государственный университет коммерции: [сайт]. - 2020. - URL: http://izron.ru.

4. Рынок труда в Таджикистане // Радио Свободная Европа[сайт].- 2020.- URL: https://www.ozodi. org/a/2250827.htm.

5. Экономическое развитие Республики Таджикистан // Министерство иностранных дел Республики Таджикистан. - Режим доступа: https://www.mfa.tj.

6. Экономические показатели для Таджикистана // ADB.- Режим доступа: https://www.adb.org/countries/ tajikistan/economy.

7. Агентство труда и занятости при Министерстве труда, миграции и занятости населения Республики Таджикистан [сайт]. - 2020. - URL: http://www.no-childlabour.tj.

8. Агентство по статистике при Президенте Республики Таджикистан [сайт]. - 2020. - URL: https://stat.tj.

9. Глобальная практика по макроэкономике, торговле и инвестициям / Всемирный банк [сайт]. - 2020. - URL: https://www.worldbank.org.

10. Макроэкономическая статистика Таджикистана / Биржевой портал № 1 [сайт].-2020. - URL: https://takeprofit.org.

11. Миграционная служба Министерства внутренних дел Республики Таджикистан [сайт]. - 2020. - URL: http:// migration.tj.

12. Национальный банк Таджикистана [сайт].-2020. - URL: http://nbt.tj.

13. Официальный сайт Министерства труда, миграции и занятости населения Республики Таджикиста [сайт].2020.-URL: http://mehnat.tj.

14. Официальный сайт Федеральной службы государственной статистики РФ [Электронный ресурс] URL: http://www.gks.ru.

15. Фахрутдинова Е.В., Юрков Д.В. Эмпирический анализ взаимосвязи качества жизни и миграции населения в субъектах Российской Федерации// Экономические науки. 2019. № 181. С.363-368.

16. Фахрутдинова Е.В. Роль социальной сферы и социальной политики в обеспечении устойчивого социальноэкономического развития страны// Экономические науки. 2009. № 57. С.7-11.

17. Kireyev A. The Macroeconomics of Remittances: The Case of Tajikistan, IMF Working Paper No. 06/2. Washington: International Monetary Fund, 2016: 17, https://www.imf.org/external/pubs/ft/wp/2006/wp0620.pdf.

18. Brown R., Olimova S. and Boboev M. (2018) Country Report on Remittances of International Migrants in Tajikistan, in Study on International Migrants' Remittances in Central Asia and South Caucasus, Asian Development Bank, http://www.adb.org/Documents/Reports/Consultant/40038-REG/40038-04-REG-TACR.pdf. 
19. Blondin, S. (2019) Environmental migrations in Central Asia: a multifaceted approach to the issue. Central Asian Survey, 38. DOI: 10.1080/02634937.2018.1519778..

20. Didenko I, Volik K, Vasilieva T, Lyeonov S, Migration, environment and country safety: analysis of touchpoints Central Asian Survey 202, 03028 (2020) https://doi.org/10.1051/e3sconf/202020203028.

21. T. Vasylieva, Yu. Bilan, I. Tiutiunyk, T. Pisula, Countries financial development and digital readiness as determinants of financial sector innovativeness, in Proceedings of the 34rd International Business Information Management Association Conference, IBIMA, 13-14 November 2019, Madrid, Spain (2019).

22. Blondin, $S$. Understanding involuntary immobility in the Bartang Valley of Tajikistan through the prism of motility Central Asian Survey 202, 03028 (2019)/ 